\title{
Known-IV Attacks on Triple Modes of Operation of Block Ciphers
}

\author{
Deukjo Hong ${ }^{1}$, Jaechul Sung ${ }^{1}$, Seokhie Hong ${ }^{1}$, Wonil Lee ${ }^{1}$, Sangjin Lee ${ }^{1}$, \\ Jongin $\mathrm{Lim}^{1}$, and Okyeon $\mathrm{Yi}^{2}$ * \\ 1 Center for Information Security Technologies (CIST), \\ Korea University, Anam Dong, Sungbuk Gu, \\ Seoul, Korea \\ \{hongdj, sjames, hsh, nice, sangjin, jilim\}@cist.korea.ac.kr \\ 2 Electronics and Telecommunications Research Institute (ETRI), \\ 161 Gajeong-dong, Yusong-Gu, Daejon, 305-350, Korea \\ \{oyyi@etri.re.kr\}
}

\begin{abstract}
With chosen-IV chosen texts, David Wagner has analyzed the multiple modes of operation proposed by Eli Biham in FSE'98. However, his method is too unrealistic. We use only known-IV chosen texts to attack many triple modes of operation which are combined with cascade operations. 123 triple modes are analyzed with complexities less than E. Biham's results. Our work shows that the securities of many triple modes decrease when the initial values are exposed.
\end{abstract}

Keywords: Block cipher, mode of operation for DES, Triple DES

\section{Introduction}

Since the appearance of DES 7], several attacks on DES and its variants have been suggested. E. Biham and Adi Shamir introduced differential cryptanalysis of DES in 1991 and 1992 34. Mitsuru Matsui analyzed DES with linear cryptanalysis in 1993 and 1994 [5]. Differential cryptanalysis and linear cryptanalysis are the most powerful methods for attacking DES. These attacks have led many people in the cryptographic community to suggest stronger replacements for DES, which can be either new cryptosystems or new modes of operation for the DES. So triple DES instead of DES has been used and applied to the modes of operation for DES - ECB, CBC, OFB, and CFB. Triple DES is even more secure but slower than DES. This reason has led to consideration of multiple modes of operation combined from several consecutive applications of single modes. In hardware implementation, the multiple modes have an advantage that their speed is the same as of single modes because the single modes can be pipelined. In particular, the triple modes were expected to be as secure as triple DES although they have DES as a building block.

\footnotetext{
* Supported by a grant of Electronics and Telecommunication Research Institute, Korea.

C. Boyd (Ed.): ASIACRYPT 2001, LNCS 2248, pp. 208221, 2001

(C) Springer-Verlag Berlin Heidelberg 2001
} 
In 1994 and 1996, E. Biham analyzed many triple modes of operation with chosen plaintexts and chosen ciphertexts, and showed that every mode considered except the the triple ECB mode is not much more secure than single modes 12 2. Considering dictionary attacks or matching-ciphertext attacks, the commonly-used triple-DES-ECB mode when used with some outer chaining technique is not much more secure than any single modes. To solve this state of affairs, E. Biham proposed 9 new block modes and 2 new stream modes of operation for DES. The complexities of attacking these new modes are conjectured to be at least $2^{112}$. The quadruple modes were conjectured to be more secure than any triple mode; furthermore, the complexity of attacking two of the quadruple modes was conjectured to be at least $2^{128}$.

In 1998, D. Wagner analyzed E. Biham's proposals [8]. Using the chosenIV chosen text queries he broke them with the complexities lower than what E. Biham has conjectured. His method utilizes an equation for an exhaustive search for a key or looks for a collision for a birthday attack. Since E. Biham's studies were premised on a more restrictive threat model that did not admit chosen-IV attacks, D. Wagner's results do not disprove E. Biham's conjectures but raise questions about the security of E. Biham's proposed modes.

D. Wagner's assumption of chosen-IV is too unrealistic, so we use knownIV chosen texts more practical than chosen-IV to re-analyze the triple modes which E. Biham analyzed. Our attacks take their place between E. Biham's and D. Wagner's in terms of controlling IVs. However, since for fixed IVs the birthday paradox is not available as D. Wagner, our attacks cannot break E. Biham's proposals. Our results show how much the security of each triple mode decreases when the initial value is exposed.

\section{Preliminaries}

In this section, we describe something to understand our attack. Note that the underlying block cipher of every mode throughout this paper is DES with 64 bit plaintext and 56 bit key.

We write $P_{0}, P_{1}, \cdots$ (or $C_{0}, C_{1}, \cdots$, respectively) for the blocks of the plaintext (or ciphertext, respectively). We number the keys $K_{1}, K_{2}, \cdots$ and the initial values $I V_{1}, I V_{2}, \cdots$ according to the order that the single-mode appears in the triple modes. The capital letters $A, B, \cdots$ are any fixed 64 -bit values if no additional explanations for them are given.

D. Wagner chose initial values and plaintexts or ciphertexts to analyze the multiple modes which E. Biham has proposed. His method searches for some equations or collisions to apply to an exhaustive search or birthday attack. Since E. Biham's multiple modes are very secure, we think that it is very hard for anyone to find a proper method to break them. However the assumption that the attacker can choose the initial value is too unrealistic. The assumption of known-IV is more practical than that of chosen-IV because the initial values require integrity rather than secrecy.

When all initial values are known, every double mode is broken by a meet-inthe-middle attack. Furthermore, all except ECB $|\mathrm{ECB}, \mathrm{CBC}| \mathrm{CBC}^{-1}, \mathrm{CBC} \mid \mathrm{OFB}$, $\mathrm{CBC}\left|\mathrm{CFB}^{-1}, \mathrm{OFB}\right| \mathrm{CBC}^{-1}, \mathrm{OFB}|\mathrm{OFB}, \mathrm{OFB}| \mathrm{CFB}^{-1}, \mathrm{CF} \mathrm{B} \mathrm{CBC}^{-1}, \mathrm{CFB} \mid \mathrm{OFB}$, 
$\mathrm{CFB} \mid \mathrm{CFB}^{-1}$ are broken by only two exhaustive searches for two keys. We search equations which isolate one key or two keys to analyze any triple modes. In the initial cases, such a key value is recovered with a $2^{56}$ exhaustive key search and then remaining two keys are with a meet-in-the middle attack. In most of the latter cases, we can apply a meet-in-the-middle attack to the equation and then find the remaining key with the exhaustive key search.

\section{Known-IV Attacks}

We analyze 123 out of 216 triple modes. Complete knowledge of IVs is useful in breaking the triple modes which have the feedbacks driven into certain middle parts or arranged in a particular direction. However, it hardly helps the attacker who tries to find the keys of the triple modes with the feedbacks to spread forward and backward.

A meet-in-the-middle attack for double ECB mode requires two known plaintexts. Using the one plaintext, we search some key candidates such that intermediate values are equal. Despite having the wrong key, it may make intermediate values equal with the probability of $2^{-64}$. We can find the right keys with a high probability by checking them for the other plaintext.

The meet-in-the-middle attacks in our work also require two equations, two chosen plaintexts, or two chosen ciphertexts. Taking this into account, we choose the plaintexts or the ciphertexts; we classify the attacks according to the choice of the texts.

\subsection{AAB-Attack}

This method can break all triple modes in which the first two modes are $\mathrm{ECB} \mid \mathrm{ECB}$. We describe the attack of $\mathrm{ECB}|\mathrm{ECB}| \mathrm{CBC}^{-1}$ as an example. We choose the plaintexts $(A, A, B)$ and obtain the ciphertexts $\left(C_{0}, C_{1}, C_{2}\right)$. In Fig. 11 the intermediate values after the first ECB component and the second ECB component are $\left(A^{\prime}, A^{\prime}, B^{\prime}\right)$ and $\left(A^{\prime \prime}, A^{\prime \prime}, B^{\prime \prime}\right)$. Then the output of the third encryption box in the first block is equal to that in the second block. Therefore, we obtain the following equation.

$$
E_{K_{3}}^{-1}\left(I V_{3} \oplus C_{0}\right)=I V_{3} \oplus C_{0} \oplus C_{1}
$$

So we may find $K_{3}$ by a $2^{56}$ exhaustive search, recognizing the right key value when the above equation holds. We expect no wrong key to survive the check with a high probability.

Finally, $K_{1}$ and $K_{2}$ can be recovered by the meet-in-the-middle attack with two plaintexts $A$ and $B$. Consequently, we use 3 chosen plaintexts to break the $\mathrm{ECB}|\mathrm{ECB}| \mathrm{CBC}^{-1}$ mode, whereas E. Biham's method requires $2^{64}$ chosen plaintexts.

\section{$3.2 \quad A A B B$-Attack}

This method can break many triple modes in which the last two modes are $\mathrm{CBC} \mid \mathrm{ECB}$. We describe the attack of $\mathrm{OFB}|\mathrm{CBC}| \mathrm{ECB}$ as an example. We 


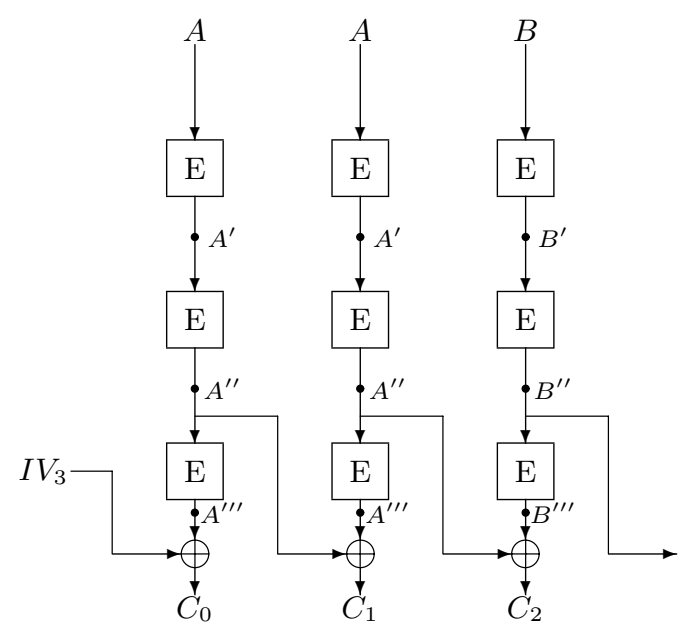

Fig. 1. Attack of $\mathrm{ECB}|\mathrm{ECB}| \mathrm{CBC}^{-1}$

choose the ciphertexts $(A, A, B, B)$ and obtain the corresponding plaintexts $\left(P_{0}, P_{1}, P_{2}, P_{3}\right)$. In Fig. 2, the intermediate values entering the second encryption boxes are $\left(A^{\prime \prime}, A^{\prime \prime}, B^{\prime \prime}, B^{\prime \prime}\right)$, where $A^{\prime}=E_{K_{3}}^{-1}(A), B^{\prime}=E_{K_{3}}^{-1}(B), A^{\prime \prime}=E_{K_{2}}^{-1}\left(A^{\prime}\right)$, and $B^{\prime \prime}=E_{K_{2}}^{-1}\left(B^{\prime}\right)$. Therefore, we obtain the following equation for the first two blocks.

$$
E_{K_{1}}\left(I V_{1}\right) \oplus E_{K_{1}}\left(E_{K_{1}}\left(I V_{1}\right)\right)=I V_{2} \oplus P_{0} \oplus P_{1} \oplus E_{K_{3}}^{-1}(A)
$$

$K_{1}$ and $K_{3}$ are founded by a meet-in-the-middle attack. The right side of the above equation is computed for each of possible key values of $K_{3}$ and the result is kept in a table. Then the left side is computed under each of possible key values of $K_{1}$ and checked whether the result appears in the table. If a pair of keys $\left(K_{1}, K_{3}\right)$ satisfies both the above and the following equations, we conclude that they are the right keys for $K_{1}$ and $K_{3}$.

$$
\begin{gathered}
E_{K_{1}}\left(E_{K_{1}}\left(E_{K_{1}}\left(I V_{1}\right)\right)\right) \oplus E_{K_{1}}\left(E_{K_{1}}\left(E_{K_{1}}\left(E_{K_{1}}\left(I V_{1}\right)\right)\right)\right) \\
=P_{2} \oplus P_{3} \oplus E_{K_{3}}^{-1}(A) \oplus E_{K_{3}}^{-1}(B)
\end{gathered}
$$

$K_{2}$ is recovered by brute force. Consequently, we use 4 chosen ciphertexts to break the OFB $|\mathrm{CBC}| \mathrm{ECB}$ mode, whereas E. Biham's method requires $2^{64}$ chosen ciphertexts.

\section{3 $A A A B$-Attack}

If the last two modes are a combination of ECB, CBC, or CFB, the triple mode is vulnerable to this attack. We will describe the application of this method to the $\mathrm{CBC}|\mathrm{CFB}| \mathrm{ECB}$. To find the keys, we choose the ciphertexts $(A, A, A, B)$, and 


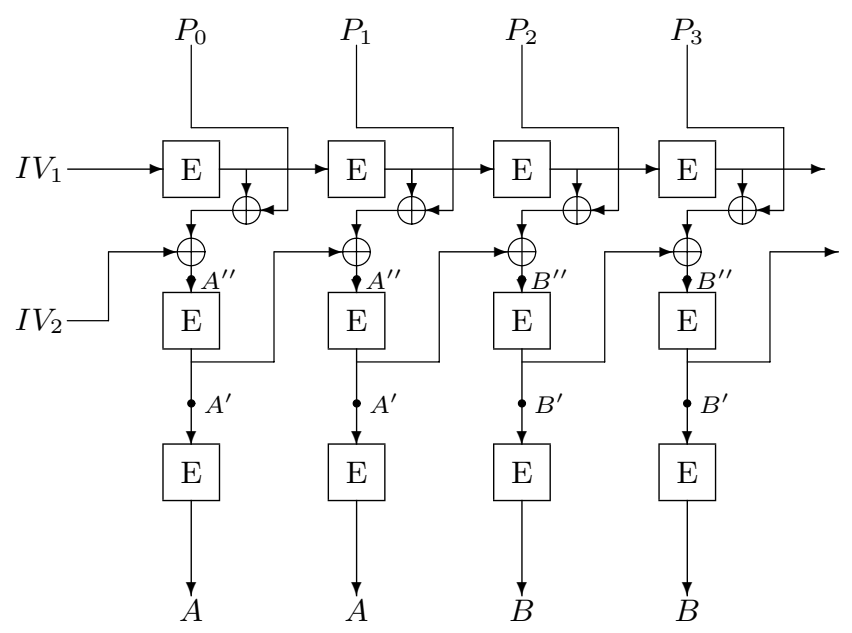

Fig. 2. Attack of $\mathrm{OFB}|\mathrm{CBC}| \mathrm{ECB}$

obtain the corresponding plaintexts $\left(P_{0}, P_{1}, P_{2}, P_{3}\right)$. In Fig. 3, the intermediate values after the first ECB component must be of the form $(?, F, F, ?)$. Therefore, the intermediate value entering the first encryption box in the second block is equal to that in the third block. For all the possible values of $K_{1}$, we check the following equation.

$$
E_{K_{1}}\left(I V_{1} \oplus P_{0}\right) \oplus E_{K_{1}}\left(E_{K_{1}}\left(I V_{1} \oplus P_{0}\right) \oplus P_{1}\right)=P_{1} \oplus P_{2}
$$

Consequently, we use 4 chosen cipehrtexts to break the $\mathrm{CBC}|\mathrm{CFB}| \mathrm{ECB}$, whereas E. Biham's method requires $2^{36}$ chosen ciphertexts.

\subsection{AAA-Attack}

This attack can break all triple modes in which the first two mode is ECB $\mid \mathrm{OFB}$. We describe explain the attack of the ECB $|\mathrm{OFB}| \mathrm{OFB}$ mode as an example. We choose the plaintexts $(A, A, A)$ and obtain the corresponding ciphertexts $\left(C_{0}, C_{1}, C_{2}\right)$. The following equations are obtained from the fact that all of the intermediate values after the first ECB mode are equal.

$$
\begin{gathered}
E_{K_{2}}\left(I V_{2}\right) \oplus E_{K_{2}}\left(E_{K_{2}}\left(I V_{2}\right)\right)=C_{0} \oplus C_{1} \oplus E_{K_{3}}\left(I V_{3}\right) \oplus E_{K_{3}}\left(E_{K_{3}}\left(I V_{3}\right)\right) \\
E_{K_{2}}\left(I V_{2}\right) \oplus E_{K_{2}}\left(E_{K_{2}}\left(E_{K_{2}}\left(I V_{2}\right)\right)\right) \\
=C_{0} \oplus C_{2} \oplus E_{K_{3}}\left(I V_{3}\right) \oplus E_{K_{3}}\left(E_{K_{3}}\left(E_{K_{3}}\left(I V_{3}\right)\right)\right)
\end{gathered}
$$

Then we can find $K_{2}$ and $K_{3}$ by a meet-in-the-middle attack. Consequently, we use 3 chosen plaintexts to break the ECB $|\mathrm{OFB}| \mathrm{OFB}$ mode, whereas E. Biham's method requires $2^{65}$ chosen plaintexts. 


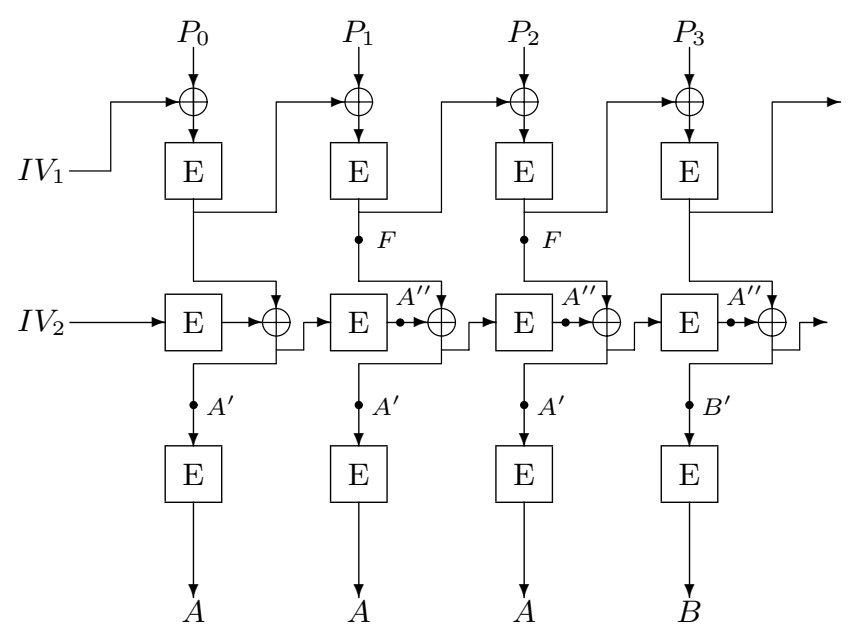

Fig. 3. Attack of $\mathrm{CBC}|\mathrm{CFB}| \mathrm{ECB}$

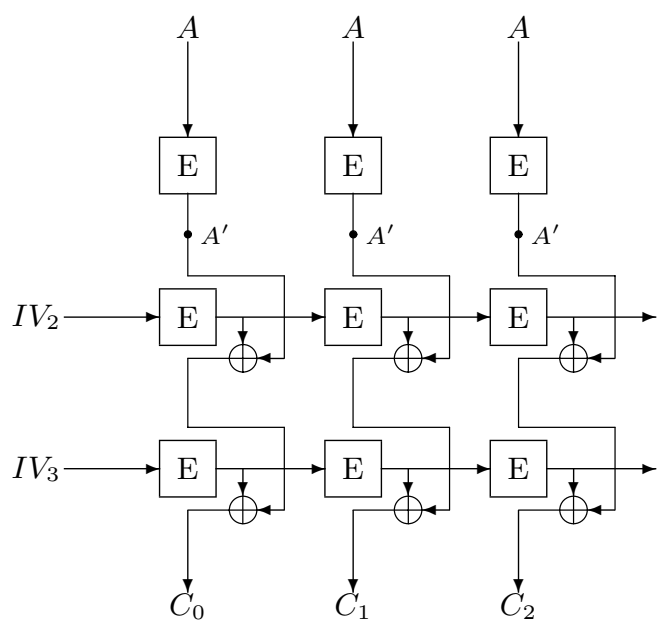

Fig. 4. Attack of ECB $|\mathrm{OFB}| \mathrm{OFB}$ 


\subsection{IVIVA-Attack}

The main targets of this attack are the triple modes in which the last mode is CFB. We explain the attack of the $\mathrm{OFB}|\mathrm{CFB}| \mathrm{CFB}$ mode as an example. We choose the ciphertexts $\left(I V_{3}, I V_{3}, A\right)$ and obtain the corresponding plaintexts $\left(P_{0}, P_{1}, P_{2}\right)$. In Fig. 5, the intermediate values after the second $\mathrm{CFB}$ component must be of the form $(B, B, ?)$, where $B=I V_{3} \oplus E_{K_{3}}\left(I V_{3}\right)$. Then, the intermediate value of the input to the second encryption box in the second block is equal to that in the third block. We use the following equation to find $K_{3}$ by brute force.

$$
E_{K_{1}}\left(E_{K_{1}}\left(I V_{1}\right)\right) \oplus E_{K_{1}}\left(E_{K_{1}}\left(E_{K_{1}}\left(I V_{1}\right)\right)\right)=P_{1} \oplus P_{2} \oplus I V_{3} \oplus A
$$

Consequently, we use 3 chosen ciphertexts to break the $\mathrm{OFB}|\mathrm{CFB}| \mathrm{CFB}$ mode, whereas E. Biham's method requires $2^{66}$ chosen cipehrtexts.

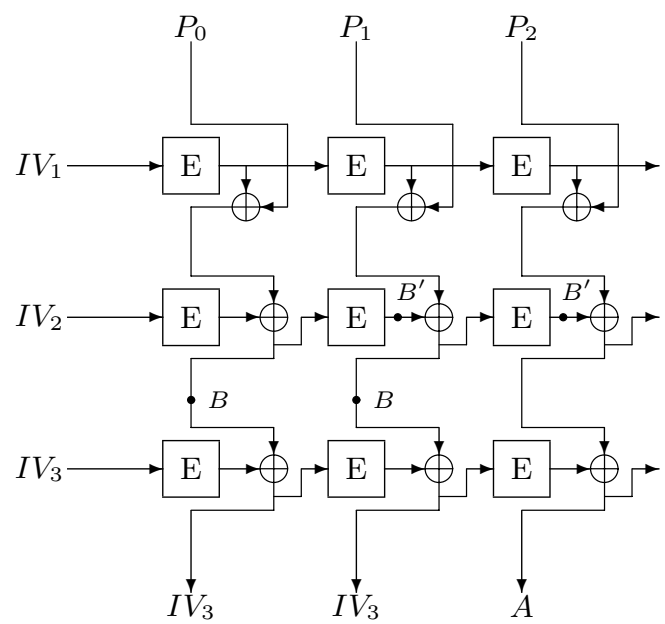

Fig. 5. Attack of $\mathrm{OFB}|\mathrm{CFB}| \mathrm{CFB}$

\subsection{IVIVIV-Attack}

This method analyzes many triple modes in which the first mode is any single mode with a feedback and that the second mode is the OFB mode. We explain the attack of the $\mathrm{CFB}|\mathrm{OFB}| \mathrm{CBC}$ mode as a example. We choose the ciphertexts $\left(I V_{3}, I V_{3}, I V_{3}\right)$ and the corresponding plaintexts $\left(P_{0}, P_{1}, P_{2}\right)$. In Fig. 6] all of the intermediate values after the second OFB component are equal. We obtain the following equation. 


$$
\begin{gathered}
E_{K_{1}}\left(I V_{1}\right) \oplus P_{0} \oplus E_{K_{2}}\left(I V_{2}\right)=E_{K_{1}}\left(E_{K_{1}}\left(I V_{1}\right) \oplus P_{0}\right) \oplus P_{1} \oplus E_{K_{2}}\left(E_{K_{2}}\left(I V_{2}\right)\right) \\
=E_{K_{1}}\left(E_{K_{1}}\left(E_{K_{1}}\left(I V_{1}\right) \oplus P_{0}\right) \oplus P_{1}\right) \oplus P_{2} \oplus E_{K_{2}}\left(E_{K_{2}}\left(E_{K_{2}}\left(I V_{2}\right)\right)\right)
\end{gathered}
$$

Then we can find $K_{1}$ and $K_{2}$ by a meet-in-the-middle attack. Consequently, we use 3 chosen ciphertexts to break the $\mathrm{CFB}|\mathrm{OFB}| \mathrm{CBC}$ mode, whereas $\mathrm{E}$. Biham's method requires $2^{66}$ chosen ciphertexts. Furthermore, it takes $5 \cdot 2^{56}$ encryption times with our attack until its three keys are found, whereas it takes $2^{66}$ encryption times with E. Biham's attack.

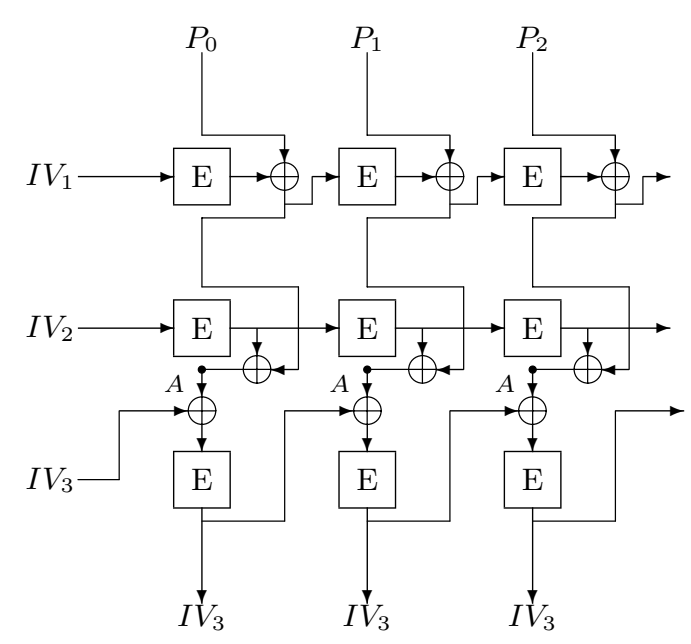

Fig. 6. Attack of $\mathrm{CFB}|\mathrm{OFB}| \mathrm{CBC}$

\subsection{IVIVIV A-Attack}

The triple CBC mode and similar modes are broken by this method. We describe the attack of the triple $\mathrm{CBC}$ mode as an example. We choose the ciphertexts $\left(I V_{3}, I V_{3}, I V_{3}, A\right)$ and obtain the corresponding plaintexts $\left(P_{0}, P_{1}, P_{2}, P_{3}\right)$. In Fig. 7 the intermediate values after the first $\mathrm{CBC}$ component must be of the form (?, $B \oplus B^{\prime}, B \oplus B^{\prime}$, ?), where $B=I V_{3} \oplus E_{K_{3}}^{-1}\left(I V_{3}\right)$ and $B^{\prime}=E_{K_{2}}^{-1}(B)$. Therefore, the second and the third blocks in the values of the input to the first encryption boxes are equal.

$$
E_{K_{1}}\left(I V_{1} \oplus P_{0}\right) \oplus E_{K_{1}}\left(E_{K_{1}}\left(I V_{1} \oplus P_{0}\right) \oplus P_{1}\right)=P_{1} \oplus P_{2}
$$

We may find $K_{1}$ by a $2^{56}$ exhaustive keysearch, recognizing the right key value when the above equation holds. Consequently, we use 4 chosen ciphertexts to break the $\mathrm{CBC}|\mathrm{CBC}| \mathrm{CBC}$ mode, whereas E. Biham's method requires $2^{34}$ chosen ciphertexts. 


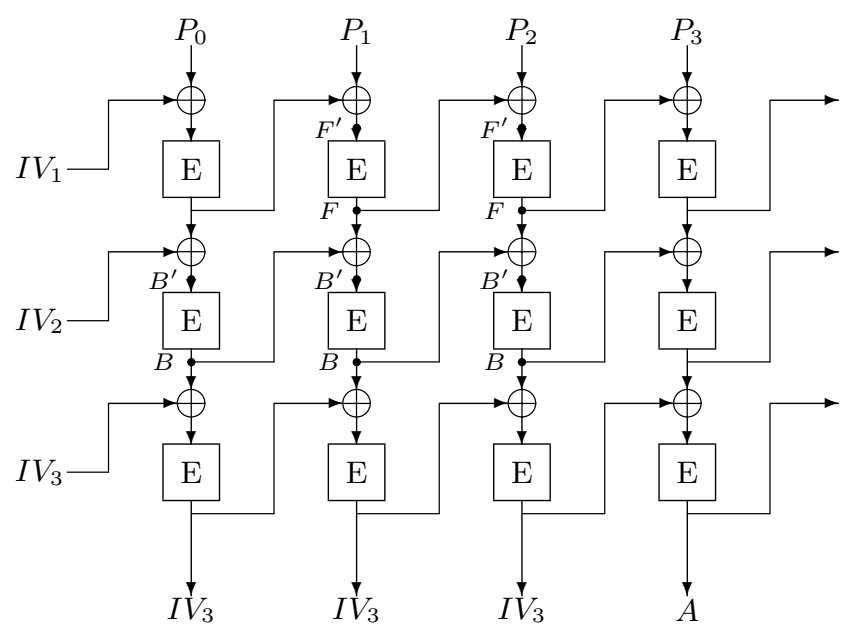

Fig. 7. Attack of $\mathrm{CBC}|\mathrm{CBC}| \mathrm{CBC}$

\subsection{IVIVAAA-Attack}

The $\mathrm{ECB}|\mathrm{CBC}| \mathrm{CFB}$ mode and the $\mathrm{CFB}|\mathrm{CBC}| \mathrm{CFB}$ mode are broken by this method. To find the keys of the ECB $|\mathrm{CBC}| \mathrm{CFB}$ mode, we choose the ciphertexts $\left(I V_{3}, I V_{3}, A, A, A\right)$ and obtain the corresponding plaintexts $\left(P_{0}, P_{1}, P_{2}, P_{3}, P_{4}\right)$. In Fig. 8 the intermediate values entering the second encryption boxes must be of the form $(B, B, ?, F, F)$, where $B=E_{K_{2}}^{-1}\left(E_{K_{3}}\left(I V_{3}\right) \oplus I V_{3}\right)$ and $F=$ $E_{K_{2}}^{-1}\left(E_{K_{3}}(A) \oplus A\right)$. Therefore, for the first and the second blocks, we obtain the following equation.

$$
E_{K_{1}}\left(P_{0}\right) \oplus E_{K_{1}}\left(P_{1}\right)=I V_{2} \oplus I V_{3} \oplus E_{K_{3}}\left(I V_{3}\right)
$$

By a meet-in-the middle attack, we find a few candidates of a pair of $\left(K_{1}, K_{3}\right)$ from the above equation. If a candidate satisfies the following equation which we obtain for the fourth and fifth blocks, we are sure that it is the right value of $\left(K_{1}, K_{3}\right)$.

$$
E_{K_{1}}\left(P_{3}\right) \oplus E_{K_{1}}\left(P_{4}\right)=E_{K_{3}}\left(I V_{3}\right) \oplus E_{K_{3}}(A)
$$

Then $K_{2}$ is recovered by an exhaustive search. Consequently, we use 5 chosen ciphertexts to break the $\mathrm{ECB}|\mathrm{CBC}| \mathrm{CFB}$ mode, whereas E. Biham's method requires $2^{34}$ chosen ciphertexts.

\section{$3.9 \quad I V I V A A A B$-Attack}

We only apply this method to the ECB $|\mathrm{CFB}| \mathrm{CBC}$ mode. To find its keys of it, we choose the ciphertexts $\left(I V_{3}, I V_{3}, A, A, A, B\right)$ and obtain the corresponding plaintexts $\left(P_{0}, P_{1}, P_{2}, P_{3}, P_{4}, P_{5}\right)$. In Fig. [9, the intermediate values after the 


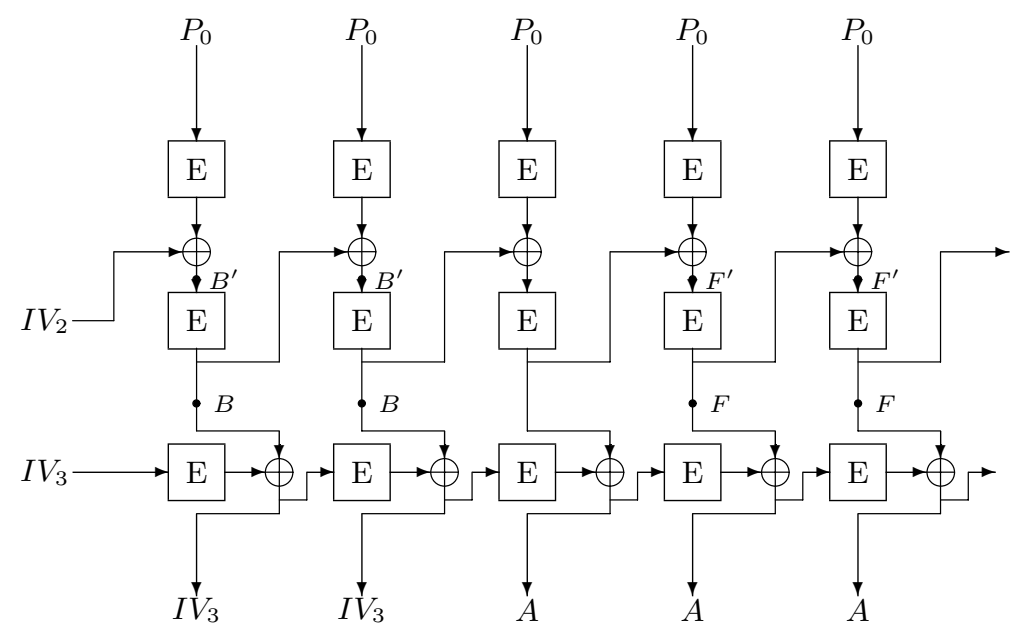

Fig. 8. Attack of $\mathrm{ECB}|\mathrm{CBC}| \mathrm{CFB}$

second CFB component must be of the form $(F, F, ?, G, G, ?)$, where $F=I V_{3} \oplus$ $E_{K_{3}}^{-1}\left(I V_{3}\right)$, and $G=A \oplus E_{K_{3}}^{-1}(A)$. Therefore, for the second and third blocks, we obtain the following equation.

$$
E_{K_{1}}\left(P_{1}\right) \oplus E_{K_{1}}\left(P_{2}\right)=E_{K_{3}}^{-1}\left(I V_{3}\right) \oplus E_{K_{3}}^{-1}(A)
$$

By a meet-in-the middle attack, we find a few candidates of a pair of $\left(K_{1}, K_{3}\right)$ from the above equation. If a candidate satisfies the following equation which we obtain for the fourth and fifth blocks, we are sure that it is the right value of $\left(K_{1}, K_{3}\right)$.

$$
E_{K_{1}}\left(P_{4}\right) \oplus E_{K_{1}}\left(P_{5}\right)=E_{K_{3}}^{-1}(A) \oplus E_{K_{3}}^{-1}(B)
$$

Then $K_{2}$ is recovered by an exhaustive search. Consequently, we use 6 chosen ciphertexts to break the $\mathrm{ECB}|\mathrm{CFB}| \mathrm{CBC}$ mode, whereas E. Biham's method requires $2^{34}$ chosen ciphertexts.

\section{Conclusion}

In this paper, we have presented the attacks to break many triple modes of operation with known-IV chosen plaintexts or chosen ciphertexts. Our results require fewer texts in cryptanalysis of triple modes than E. Biham's. We have analyzed 123 among 216 triple modes of operation. If the initial values are known, the triple modes which have the feedbacks driven into certain middle parts or arranged in a direction may be much weaker than under E. Biham's assumption. They are broken with about 3-4 chosen plaintexts or ciphertexts, $2^{58}$ encryptions, and $2^{56}$ memories. However, we could not find the proper method to attack the 


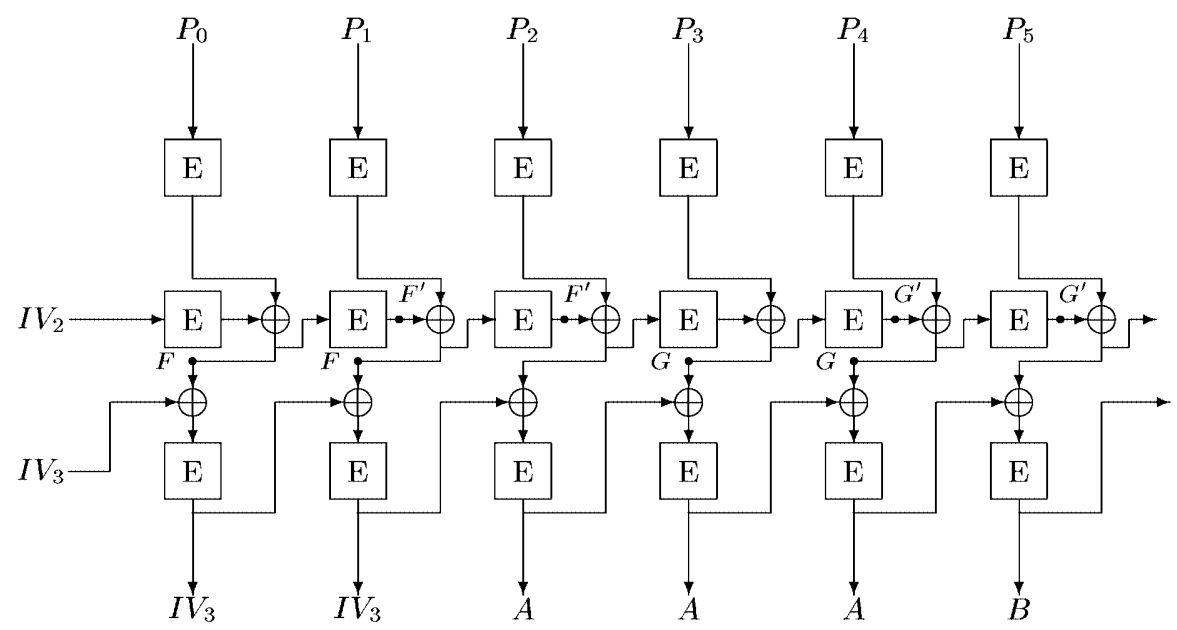

Fig. 9. Attack of $\mathrm{ECB}|\mathrm{CFB}| \mathrm{CBC}$

others when trying to find the keys of the triple modes which have the feedbacks to spread forward and backward. We leave the problem of such triple modes open.

\section{References}

1. E. Biham. Cryptanalysis of multiple modes of operation. Journal of Cryptology, 011:45-58, 1998.

2. E. Biham. Cryptanalysis of triple modes of operation. Journal of Cryptology, 012:161-184, 1999.

3. Eli Biham and Adi Shamir. Differential cryptanalysis of DES-like cryptosystems. J. Cryptology, 4(1):3-72, 1991.

4. Eli Biham and Adi Shamir. Differential cryptanalysis of the full 16-round DES. In E. F. Brickell, editor, Advances in Cryptology - CRYPTO'92, volume 740 of Lecture Note in Computer Science, pages 487-496. Springer-Verlag, 1993.

5. Mitsuru Matsui. Linear cryptanalysis method for DES cipher. In T. Helleseth, editor, Advances in Cryptology - EUROCRYPT'93, volume 765 of Lecture Notes in Computer Science, pages 386-397. Springer-Verlag, 1994.

6. Mitsuru Matsui. On correlation between the order of s-boxes and the strength of DES. In Advances in Cryptology - EUROCRYPT'94, volume 950 of Lecture Notes in Computer Science, pages 366-375. Springer-Verlag, 1995.

7. National Bureau of Standards. Data Encryption Standard. FIPS Pub. 46, 1977.

8. D. Wagner. Cryptanalysis of some recently-proposed multiple modes of operation. In FSE'98, volume 1372 of Lecture Notes in Computer Science, 1998.

\section{Appendix}

In this appendix we list our result. We follow Biham's notation of the complexity, which consists of three parameters: the number of plaintexts/the number of steps 
of the attack(the time of encryptions)/the required memory size. 'Biham' is the result in 2 corresponding to ours. We compute some E. Biham's complexities in detail when the differences between our results and them are relatively small.

Table 1. $A A B$-attack

\begin{tabular}{|c|c|c|c|}
\hline Mode & Complexity & Biham & Inverse \\
\hline$\overline{\mathrm{ECB}}|\mathrm{ECB}| \mathrm{CBC}$ & $3 / 4 \cdot 2^{56} / 2^{56}$ & $2^{33} / 2^{58} / 2^{56}$ & $\mathrm{CBC}^{-1}|\mathrm{ECB}| \mathrm{ECB}$ \\
\hline $\mathrm{ECB}|\mathrm{ECB}| \mathrm{CBC}^{-1}$ & $3 / 3 \cdot 2^{56} / 2^{56}$ & $2^{64} / 2^{58} / 2^{56}$ & $\mathrm{CBC}|\mathrm{ECB}| \mathrm{ECB}$ \\
\hline $\mathrm{ECB}|\mathrm{ECB}| \mathrm{OFB}$ & $3 / 4 \cdot 2^{56} / 2^{56}$ & $2^{64} / 2^{58} / 2^{56}$ & $\mathrm{OFB}|\mathrm{ECB}| \mathrm{ECB}$ \\
\hline $\mathrm{ECB}|\mathrm{ECB}| \mathrm{CFB}$ & $3 / 4 \cdot 2^{56} / 2^{56}$ & $2^{33} / 2^{58} / 2^{56}$ & $\mathrm{CFB}^{-1}|\mathrm{ECB}| \mathrm{ECB}$ \\
\hline $\mathrm{ECB}|\mathrm{ECB}| \mathrm{CFB}^{-1}$ & $3 / 4 \cdot 2^{56} / 2^{56}$ & $2^{64} / 2^{58} / 2^{56}$ & $\mathrm{CFB}|\mathrm{ECB}| \mathrm{ECB}$ \\
\hline
\end{tabular}

Table 2. $A A B B$-attack

\begin{tabular}{|c|c|c|c|}
\hline Mode & Complexity & Biham & Inverse \\
\hline $\mathrm{ECB}|\mathrm{CBC}| \mathrm{ECB}$ & $4 / 4 \cdot 2^{56} / 2^{56}$ & $5 / 2^{59} /-$ & $\mathrm{ECB}\left|\mathrm{CBC}^{-1}\right| \mathrm{ECB}$ \\
\hline $\mathrm{CBC}^{-1}|\mathrm{CBC}| \mathrm{ECB}$ & $4 / 4 \cdot 2^{56} / 2^{56}$ & $5 / 2^{59} /-$ & $\mathrm{ECB}\left|\mathrm{CBC}^{-1}\right| \mathrm{CBC}$ \\
\hline $\mathrm{CBC}|\mathrm{CBC}| \mathrm{ECB}$ & $4 / 4 \cdot 2^{56} / 2^{56}$ & $2^{34} / 2^{59} / 2^{33}$ & $\mathrm{ECB}\left|\mathrm{CBC}^{-1}\right| \mathrm{CBC}^{-1}$ \\
\hline $\mathrm{OFB}|\mathrm{CBC}| \mathrm{ECB}$ & $4 / 4 \cdot 2^{56} / 2^{56}$ & $2^{64} / 5 \cdot 2^{56} /-$ & $\mathrm{ECB}\left|\mathrm{CBC}^{-1}\right| \mathrm{OFB}$ \\
\hline $\mathrm{CFB}^{-1}|\mathrm{CBC}| \mathrm{ECB}$ & $4 / 4 \cdot 2^{56} / 2^{56}$ & $5 / 2^{59} /-$ & $\mathrm{ECB}\left|\mathrm{CBC}^{-1}\right| \mathrm{CFB}$ \\
\hline $\mathrm{CFB}|\mathrm{CBC}| \mathrm{ECB}$ & $4 / 4 \cdot 2^{56} / 2^{56}$ & $2^{36} / 2^{59} / 2^{33}$ & $\mathrm{ECB}\left|\mathrm{CBC}^{-1}\right| \mathrm{CFB}^{-1}$ \\
\hline
\end{tabular}

Table 3. $A A A B$-attack

\begin{tabular}{|c|c|c|c|}
\hline Mode & Complexity & Biham & Inverse \\
\hline $\mathrm{ECB}|\mathrm{CBC}| \mathrm{CBC}$ & $4 / 4 \cdot 2^{56} / 2^{56}$ & $2^{33} / 2^{59} / 2^{33}$ & $\mathrm{CBC}^{-1}\left|\mathrm{CBC}^{-1}\right| \mathrm{ECB}$ \\
\hline $\mathrm{CBC}^{-1}|\mathrm{CBC}| \mathrm{ECB}$ & $4 / 4 \cdot 2^{56} / 2^{56}$ & $5 / 2^{59} /-$ & $\mathrm{ECB}\left|\mathrm{CBC}^{-1}\right| \mathrm{CBC}$ \\
\hline $\mathrm{CBC}|\mathrm{CBC}| \mathrm{ECB}$ & $4 / 4 \cdot 2^{56} / 2^{56}$ & $2^{34} / 2^{59} / 2^{33}$ & $\mathrm{ECB}\left|\mathrm{CBC}^{-1}\right| \mathrm{CBC}^{-1}$ \\
\hline $\mathrm{CFB}^{-1}|\mathrm{CBC}| \mathrm{ECB}$ & $4 / 4 \cdot 2^{56} / 2^{56}$ & $5 / 2^{59} /-$ & $\mathrm{ECB}\left|\mathrm{CBC}^{-1}\right| \mathrm{CFB}$ \\
\hline $\mathrm{CBC}^{-1}|\mathrm{CFB}| \mathrm{ECB}$ & $4 / 4 \cdot 2^{56} / 2^{56}$ & $4 / 5 \cdot 2^{56} /-$ & $\mathrm{ECB}\left|\mathrm{CFB}^{-1}\right| \mathrm{CBC}$ \\
\hline $\mathrm{CBC}|\mathrm{CFB}| \mathrm{ECB}$ & $4 / 4 \cdot 2^{56} / 2^{56}$ & $2^{36} / 2^{59} / 2^{33}$ & $\mathrm{ECB}\left|\mathrm{CFB}^{-1}\right| \mathrm{CBC}^{-1}$ \\
\hline $\mathrm{OFB}|\mathrm{CFB}| \mathrm{ECB}$ & $4 / 5 \cdot 2^{56} / 2^{56}$ & $2^{64} / 5 \cdot 2^{56} /-$ & $\mathrm{ECB}\left|\mathrm{CFB}^{-1}\right| \mathrm{OFB}$ \\
\hline $\mathrm{CFB}^{-1}|\mathrm{CFB}| \mathrm{ECB}$ & $4 / 4 \cdot 2^{56} / 2^{56}$ & $4 / 5 \cdot 2^{56} /-$ & $\mathrm{ECB}\left|\mathrm{CFB}^{-1}\right| \mathrm{CFB}$ \\
\hline $\mathrm{CFB}|\mathrm{CFB}| \mathrm{ECB}$ & $4 / 5 \cdot 2^{56} / 2^{56}$ & $2^{34} / 2^{59} / 2^{33}$ & $\mathrm{ECB}\left|\mathrm{CFB}^{-1}\right| \mathrm{CFB}^{-1}$ \\
\hline $\mathrm{CBC}^{-1}|\mathrm{CBC}| \mathrm{CBC}$ & $4 / 4 \cdot 2^{56} / 2^{56}$ & $2^{34} / 2^{59} / 2^{33}$ & $\mathrm{CBC}^{-1}\left|\mathrm{CBC}^{-1}\right| \mathrm{CBC}$ \\
\hline $\mathrm{OFB}|\mathrm{CBC}| \mathrm{CBC}$ & $4 / 5 \cdot 2^{56} / 2^{56}$ & $2^{66} / 2^{59} /-$ & $\mathrm{CBC}^{-1}\left|\mathrm{CBC}^{-1}\right| \mathrm{OFB}$ \\
\hline $\mathrm{CFB}^{-1}|\mathrm{CBC}| \mathrm{CBC}$ & $4 / 4 \cdot 2^{56} / 2^{56}$ & $2^{34} / 2^{59} / 2^{33}$ & $\mathrm{CBC}^{-1}\left|\mathrm{CBC}^{-1}\right| \mathrm{CFB}$ \\
\hline
\end{tabular}


Table 4. $A A A$-attack

\begin{tabular}{|c|c|c|c|}
\hline Mode & Complexity & Biham & Inverse \\
\hline$\overline{\mathrm{ECB}}|\mathrm{OFB}| \mathrm{ECB}$ & $3 / 5 \cdot 2^{56} / 2^{56}$ & $2^{64} / 5 \cdot 2^{56} / 2^{56}$ & itself \\
\hline $\mathrm{ECB}|\mathrm{OFB}| \mathrm{CBC}$ & $3 / 5 \cdot 2^{56} / 2^{56}$ & $2^{64} / 5 \cdot 2^{56} / 2^{56}$ & $\mathrm{CBC}^{-1}|\mathrm{OFB}| \mathrm{ECB}$ \\
\hline $\mathrm{ECB}|\mathrm{OFB}| \mathrm{CBC}^{-1}$ & $3 / 5 \cdot 2^{56} / 2^{56}$ & $2^{65} / 2^{65} /-$ & $\mathrm{CBC}|\mathrm{OFB}| \mathrm{ECB}$ \\
\hline $\mathrm{ECB}|\mathrm{OFB}| \mathrm{OFB}$ & $3 / 5 \cdot 2^{56} / 2^{56}$ & $2^{65} / 2^{65} / 2^{65}$ & $\mathrm{OFB}|\mathrm{OFB}| \mathrm{ECB}$ \\
\hline $\mathrm{ECB}|\mathrm{OFB}| \mathrm{CFB}$ & $3 / 5 \cdot 2^{56} / 2^{56}$ & $2^{64} / 5 \cdot 2^{56} / 2^{56}$ & $\mathrm{CFB}^{-1}|\mathrm{OFB}| \mathrm{ECB}$ \\
\hline $\mathrm{ECB}|\mathrm{OFB}| \mathrm{CFB}^{-1}$ & $3 / 5 \cdot 2^{56} / 2^{56}$ & $2^{65} / 2^{65} /-$ & $\mathrm{CFB}|\mathrm{OFB}| \mathrm{ECB}$ \\
\hline
\end{tabular}

Table 5. $I V I V A$-attack

\begin{tabular}{|c|c|c|c|}
\hline Mode & Complexity & Biham & Inverse \\
\hline $\mathrm{ECB}|\mathrm{CFB}| \mathrm{CFB}$ & $3 / 4 \cdot 2^{56} / 2^{56}$ & $2^{34} / 2^{59} / 2^{33}$ & $\mathrm{CFB}^{-1}\left|\mathrm{CFB}^{-1}\right| \mathrm{ECB}$ \\
\hline $\mathrm{CBC}|\mathrm{ECB}| \mathrm{CBC}$ & $3 / 3 \cdot 2^{56} / 2^{56}$ & $2^{34} / 2^{59} / 2^{33}$ & $\mathrm{CBC}^{-1}|\mathrm{ECB}| \mathrm{CBC}^{-1}$ \\
\hline $\mathrm{CBC}|\mathrm{ECB}| \mathrm{CFB}$ & $3 / 3 \cdot 2^{56} / 2^{56}$ & $2^{34} / 2^{59} / 2^{33}$ & $\mathrm{CFB}^{-1}|\mathrm{ECB}| \mathrm{CBC}^{-1}$ \\
\hline $\mathrm{OFB}|\mathrm{ECB}| \mathrm{CBC}$ & $3 / 4 \cdot 2^{56} / 2^{56}$ & $2^{64} / 5 \cdot 2^{56} /-$ & $\mathrm{CBC}^{-1}|\mathrm{ECB}| \mathrm{OFB}$ \\
\hline $\mathrm{CBC}^{-1}|\mathrm{ECB}| \mathrm{CBC}$ & $3 / 4 \cdot 2^{56} / 2^{56}$ & $4 / 5 \cdot 2^{56} /-$ & itself \\
\hline $\mathrm{CBC}^{-1}|\mathrm{ECB}| \mathrm{CFB}$ & $3 / 4 \cdot 2^{56} / 2^{56}$ & $4 / 5 \cdot 2^{56} /-$ & $\mathrm{CFB}^{-1}|\mathrm{ECB}| \mathrm{CBC}$ \\
\hline $\mathrm{CFB}|\mathrm{ECB}| \mathrm{CBC}$ & $3 / 4 \cdot 2^{56} / 2^{56}$ & $2^{34} / 2^{59} / 2^{33}$ & $\mathrm{CBC}^{-1}|\mathrm{ECB}| \mathrm{CFB}^{-1}$ \\
\hline $\mathrm{CBC}^{-1}|\mathrm{CFB}| \mathrm{CFB}$ & $3 / 4 \cdot 2^{56} / 2^{56}$ & $2^{34} / 2^{59} / 2^{33}$ & $\mathrm{CFB}^{-1}\left|\mathrm{CFB}^{-1}\right| \mathrm{CBC}$ \\
\hline $\mathrm{OFB}|\mathrm{ECB}| \mathrm{CFB}$ & $3 / 4 \cdot 2^{56} / 2^{56}$ & $2^{64} / 5 \cdot 2^{56} /-$ & $\mathrm{CFB}^{-1}|\mathrm{ECB}| \mathrm{OFB}$ \\
\hline $\mathrm{OFB}|\mathrm{CFB}| \mathrm{CFB}$ & $3 / 5 \cdot 2^{56} / 2^{56}$ & $2^{66} / 2^{59} /-$ & $\mathrm{CFB}^{-1}\left|\mathrm{CFB}^{-1}\right| \mathrm{OFB}$ \\
\hline $\mathrm{CFB}|\mathrm{ECB}| \mathrm{CFB}$ & $3 / 4 \cdot 2^{56} / 2^{56}$ & $2^{34} / 2^{59} / 2^{33}$ & $\mathrm{CFB}^{-1}|\mathrm{ECB}| \mathrm{CFB}^{-1}$ \\
\hline $\mathrm{CFB}|\mathrm{CFB}| \mathrm{CFB}$ & $3 / 5 \cdot 2^{56} / 2^{56}$ & $2^{34} / 2^{60} / 2^{33}$ & $\mathrm{CFB}^{-1}\left|\mathrm{CFB}^{-1}\right| \mathrm{CFB}^{-1}$ \\
\hline $\mathrm{CFB}^{-1}|\mathrm{CFB}| \mathrm{CFB}$ & $3 / 4 \cdot 2^{56} / 2^{56}$ & $2^{34} / 2^{59} / 2^{33}$ & $\mathrm{CFB}^{-1}\left|\mathrm{CFB}^{-1}\right| \mathrm{CFB}$ \\
\hline $\mathrm{CFB}^{-1}|\mathrm{ECB}| \mathrm{CFB}$ & $3 / 4 \cdot 2^{56} / 2^{56}$ & $4 / 5 \cdot 2^{56} /-$ & itself \\
\hline
\end{tabular}

Table 6. $I V I V I V$-attack

\begin{tabular}{llll}
\hline Mode & Complexity & Biham & Inverse \\
\hline $\mathrm{CBC}|\mathrm{OFB}| \mathrm{CBC}$ & $3 / 5 \cdot 2^{56} / 2^{56}$ & $2^{66} / 2^{66} /-$ & $\mathrm{CBC}^{-1}|\mathrm{OFB}| \mathrm{CBC}^{-1}$ \\
$\mathrm{CBC}|\mathrm{OFB}| \mathrm{CFB}$ & $3 / 5 \cdot 2^{56} / 2^{56}$ & $2^{66} / 2^{66} /-$ & $\mathrm{CFB}^{-1}|\mathrm{OFB}| \mathrm{CBC}^{-1}$ \\
$\mathrm{CBC}{ }^{-1}|\mathrm{OFB}| \mathrm{CBC}$ & $3 / 5 \cdot 2^{56} / 2^{56}$ & $2^{66} / 5 \cdot 2^{56} /-$ & itself \\
$\mathrm{OFB}|\mathrm{OFB}| \mathrm{CBC}$ & $3 / 5 \cdot 2^{56} / 2^{56}$ & $2^{65} / 2^{65} / 2^{65}$ & $\mathrm{CBC}^{-1}|\mathrm{OFB}| \mathrm{OFB}$ \\
$\mathrm{CBC}{ }^{-1}|\mathrm{OFB}| \mathrm{CFB}$ & $3 / 5 \cdot 2^{56} / 2^{56}$ & $2^{66} / 5 \cdot 2^{56} /-$ & $\mathrm{CFB}^{-1}|\mathrm{OFB}| \mathrm{CBC}$ \\
$\mathrm{CFB}|\mathrm{OFB}| \mathrm{CBC}$ & $3 / 5 \cdot 2^{56} / 2^{56}$ & $2^{66} / 2^{66} /-$ & $\mathrm{CBC}^{-1}|\mathrm{OFB}| \mathrm{CFB}^{-1}$ \\
$\mathrm{OFB}|\mathrm{OFB}| \mathrm{CFB}$ & $3 / 5 \cdot 2^{56} / 2^{56}$ & $2^{65} / 2^{65} / 2^{65}$ & $\mathrm{CFB}^{-1}|\mathrm{OFB}| \mathrm{OFB}$ \\
$\mathrm{CFB}|\mathrm{OFB}| \mathrm{CFB}$ & $3 / 5 \cdot 2^{56} / 2^{56}$ & $2^{66} / 2^{66} /-$ & $\mathrm{CFB}^{-1}|\mathrm{OFB}| \mathrm{CFB}^{-1}$ \\
$\mathrm{CFB}^{-1}|\mathrm{OFB}| \mathrm{CFB}$ & $3 / 5 \cdot 2^{56} / 2^{56}$ & $2^{66} / 5 \cdot 2^{56} /-$ & itself \\
\hline
\end{tabular}


Table 7. IVIVIVA-attack

\begin{tabular}{|c|c|c|c|}
\hline Mode & Complexity & Biham & Inverse \\
\hline$\overline{\mathrm{CBC}}|\mathrm{CBC}| \mathrm{CBC}$ & $4 / 4 \cdot 2^{56} / 2^{56}$ & $2^{34} / 2^{60} / 2^{33}$ & $\mathrm{CBC}^{-1}\left|\mathrm{CBC}^{-1}\right| \mathrm{CBC}^{-1}$ \\
\hline $\mathrm{CBC}|\mathrm{CBC}| \mathrm{CFB}$ & $4 / 4 \cdot 2^{56} / 2^{56}$ & $2^{34} / 2^{60} / 2^{33}$ & $\mathrm{CFB}^{-1}\left|\mathrm{CBC}^{-1}\right| \mathrm{CBC}^{-1}$ \\
\hline $\mathrm{CBC}|\mathrm{CFB}| \mathrm{CBC}$ & $4 / 4 \cdot 2^{56} / 2^{56}$ & $2^{34} / 2^{60} / 2^{33}$ & $\mathrm{CBC}^{-1}\left|\mathrm{CFB}^{-1}\right| \mathrm{CBC}^{-1}$ \\
\hline $\mathrm{CBC}|\mathrm{CFB}| \mathrm{CFB}$ & $4 / 4 \cdot 2^{56} / 2^{56}$ & $2^{34} / 2^{60} / 2^{33}$ & $\mathrm{CFB}^{-1}\left|\mathrm{CFB}^{-1}\right| \mathrm{CBC}^{-1}$ \\
\hline $\mathrm{CBC}^{-1}|\mathrm{CBC}| \mathrm{CFB}$ & $4 / 4 \cdot 2^{56} / 2^{56}$ & $5 / 5 \cdot 2^{56} / 2^{56}$ & $\mathrm{CFB}^{-1}\left|\mathrm{CBC}^{-1}\right| \mathrm{CBC}$ \\
\hline $\mathrm{CFB}|\mathrm{CBC}| \mathrm{CBC}$ & $4 / 4 \cdot 2^{56} / 2^{56}$ & $2^{34} / 2^{60} / 2^{33}$ & $\mathrm{CBC}^{-1}\left|\mathrm{CBC}^{-1}\right| \mathrm{CFB}^{-1}$ \\
\hline $\mathrm{CBC}^{-1}|\mathrm{CFB}| \mathrm{CBC}$ & $4 / 4 \cdot 2^{56} / 2^{56}$ & $5 / 5 \cdot 2^{56} /-$ & $\mathrm{CBC}^{-1}\left|\mathrm{CFB}^{-1}\right| \mathrm{CBC}$ \\
\hline $\mathrm{OFB}|\mathrm{CFB}| \mathrm{CBC}$ & $4 / 5 \cdot 2^{56} / 2^{56}$ & $2^{66} / 2^{59} /-$ & $\mathrm{CBC}^{-1}\left|\mathrm{CFB}^{-1}\right| \mathrm{OFB}$ \\
\hline $\mathrm{CFB}^{-1}|\mathrm{CFB}| \mathrm{CBC}$ & $4 / 4 \cdot 2^{56} / 2^{56}$ & $5 / 5 \cdot 2^{56} /-$ & $\mathrm{CBC}^{-1}\left|\mathrm{CFB}^{-1}\right| \mathrm{CFB}$ \\
\hline $\mathrm{CFB}|\mathrm{CFB}| \mathrm{CBC}$ & $4 / 4 \cdot 2^{56} / 2^{56}$ & $2^{34} / 2^{60} / 2^{33}$ & $\mathrm{CBC}^{-1}\left|\mathrm{CFB}^{-1}\right| \mathrm{CFB}^{-1}$ \\
\hline $\mathrm{OFB}|\mathrm{CBC}| \mathrm{CFB}$ & $4 / 5 \cdot 2^{56} / 2^{56}$ & $2^{66} / 2^{59} /-$ & $\mathrm{CFB}^{-1}\left|\mathrm{CBC}^{-1}\right| \mathrm{OFB}$ \\
\hline $\mathrm{CFB}^{-1}|\mathrm{CBC}| \mathrm{CFB}$ & $4 / 4 \cdot 2^{56} / 2^{56}$ & $5 / 5 \cdot 2^{56} /-$ & $\mathrm{CFB}^{-1}\left|\mathrm{CBC}^{-1}\right| \mathrm{CFB}$ \\
\hline
\end{tabular}

Table 8. IVIVAAA-attack

\begin{tabular}{llll}
\hline Mode & Complexity & Biham & Inverse \\
\hline ECB $|\mathrm{CBC}| \mathrm{CFB}$ & $5 / 4 \cdot 2^{56} / 2^{56}$ & $2^{34} / 2^{59} / 2^{33}$ & $\mathrm{CFB}^{-1}\left|\mathrm{CBC}^{-1}\right| \mathrm{ECB}^{5}$ \\
$\mathrm{CFB}|\mathrm{CBC}| \mathrm{CFB}$ & $5 / 4 \cdot 2^{56} / 2^{56}$ & $2^{34} / 2^{60} / 2^{33}$ & $\mathrm{CFB}^{-1}\left|\mathrm{CBC}^{-1}\right| \mathrm{CFB}^{-1}$ \\
\hline
\end{tabular}

Table 9. $I V I V A A A B$-attack

\begin{tabular}{llll}
\hline Mode & Complexity & Biham & Inverse \\
\hline $\mathrm{CBC}|\mathrm{CFB}| \mathrm{CBC}$ & $6 / 5 \cdot 2^{56} / 2^{56}$ & $2^{34} / 2^{59} / 2^{33}$ & $\mathrm{CBC}^{-1}\left|\mathrm{CFB}^{-1}\right| \mathrm{ECB}$ \\
\hline
\end{tabular}

